\title{
THE EFFECTS OF CLIMATIC VARIABLES AND CROP AREA ON MAIZE YIELD AND VARIABILITY IN GHANA
}

\author{
Henry De-Graft Acquah, Clement Kweku Kyei, Researchers \\ Department of Agricultural Economics and Extension \\ University of Cape Coast, Cape Coast, Ghana \\ Phone: +00233245543956, E-mail: henrydegraftacquah@yahoo.com
}

Received September 13, 2012

\begin{abstract}
Climate change tends to have negative effects on crop yield through its influence on crop production. Understanding the relationship between climatic variables and crop area on the mean and variance of crop yield will facilitate development of appropriate policies to cope with climate change. This paper examines the effects of climatic variables and crop area on the mean and variance of maize yield in Ghana. The Just and Pope stochastic production function using the Cobb-Douglas functional form was employed. The results show that average maize yield is positively related to crop area and negatively related to rainfall and temperature. Furthermore, increase in crop area and temperature will enlarge maize yield variability while rainfall increase will decrease the variability in maize yield.
\end{abstract}

\section{KEY WORDS}

Climatic variables; Mean yield; Yield variability; Production function; Fixed effect model; Panel data.

Agriculture plays a significant role in the economies of most countries in Sub-Saharan Africa. In Ghana, agriculture employs about $60 \%$ of the population and contributes to about $30 \%$ of the Gross Domestic Product (GDP) (Ministry of Food and Agriculture [MoFA], 2011). However, the agricultural sector is highly vulnerable to the negative impacts of climate change and climate variability as $97 \%$ of agricultural land in SubSaharan Africa is rainfed (Rockström et al., 2004). Generally, temperature increase will reduce yields and quality of food-crops thereby worsening vulnerability in food supply. Similarly, changes in precipitation patterns i.e., intensive rain concentrated in a particular month has a devastating effect on crop production (Abrol \& Ingram, 1996).

Several studies have investigated the impact of climate change on crop yield using either simulation models (Rosenzweig \& Parry, 1994; Rosenzweig et al., 2001; Aggarwal \& Mall, 2002) or regression models (Lobell \& Field, 2007; You et al., 2009; Joshi et al., 2011). The focuses of these studies have been to estimate the impact of climate change on only mean crop yield. Mearns et al. (1997) asserts that by neglecting the impact of climate change on crop yield variability and focusing on mean crop yield, these studies provides limited information. This is particularly important in Sub-Saharan Africa where growing evidence show that variability in crop yield is as a result of weather variability. However, Anderson and Hazell argue that although yield variability mostly depend on weather, sometimes it can be worsened by the adoption of high-yielding varieties and uniform agronomic practices. Although recent studies (Chen et al., 2004; Isik \& Devadoss, 2006) have considered the impact of climate change on the mean and variance of crop yield, in Ghana there is no known study available.

The purpose of this paper is to estimate the impact of climate change on the mean and variance of maize yield in Ghana using the Just and Pope $(1978,1979)$ production function. Maize is an important staple in Ghana and contributes over $20 \%$ of the incomes earned by smallholder farmers in Ghana. Notwithstanding the importance of the crop, the direction and size of the effects of climatic variables and crop area on yield distribution is unknown. Understanding this will help formulate policies to reduce yield variability and manage market risk. 


\section{MATERIALS AND METHODS}

Desk research was used to obtain secondary data from the Statistical, Research and Information Directorate (SRID) of the Ministry of Food and Agriculture (MoFA) and the Metrological Services Department of Ghana. The use of secondary data is essential to adequately capture past weather patterns and their effect on maize production in the study area. This study considered the five major maize growing regions in Ghana using data from 1992 to 2010. The choice of the starting date is because of data availability. Observed average regional maize yields and the corresponding cultivated areas are used for the study. Additionally, observed average regional growing season rainfall and temperature values are used.

To investigate the impact of climate change on average crop yield and crop yield variability, most studies (Chen et al., 2004; Isik \& Devadoss, 2006) employ the stochastic production function developed by Just and Pope (1978). The intuition behind the stochastic production function is that a production function can be specified as a sum of two components: one associated with the output level and the other linked to variability of output.

Generally, the Just and Pope production function is specified as:

$$
\begin{aligned}
& \mathrm{Y}=\mathrm{f}(\mathrm{X}, \beta)+\mathrm{h}(\mathrm{X}, \alpha)^{0.5} \square \\
& \mathrm{E}(\square)=0, \operatorname{var}(\square)=1
\end{aligned}
$$

where $\mathrm{Y}$ is output, $\mathrm{X}$ is a vector of explanatory variables. $\alpha$ and $\beta$ are unknown parameters to be estimated. $\varepsilon$ is a stochastic disturbance. $\mathrm{f}($.$) is the$ mean function that relates $X$ to average output and $h($.$) is the variance function that relates X$ to the standard deviation of output. Equation (1) allows the explanatory variables to affect both the average and the variance of maize yield. Following Isik and Devadoss (2006), equation (1) decomposes as:

$$
\begin{aligned}
& Y_{i t}=f\left(X_{i t}, \beta\right)+\mu_{i t} \\
& \mu_{i t}=\square_{i t}+h\left(X_{i t}, \alpha\right)^{0.5}
\end{aligned}
$$

where $Y_{i t}$ is maize yield for the $i^{\text {th }}$ region at year $\mathrm{t}, \mathrm{X}_{\mathrm{it}}$ is the vector of explanatory variables (rainfall, temperature and crop area) considered for the $\mathrm{i}^{\text {th }}$ region at year $\mathrm{t}, \square_{\mathrm{it}}$ is an error term with mean zero and variance equals to 1 to ensure positive output variance (Isik \& Devadoss, 2006).
The stochastic production function given by equation (2) has traditionally been estimated using either maximum likelihood estimation (MLE) or a three-stage estimation procedure involving feasible generalized least squares (FGLS) following Just and Pope $(1978,1979)$. Most empirical studies have used the FGLS approach but MLE is more efficient and unbiased than FLGS estimation in the case of small samples (Saha et al. 1997). Given the size of our sample, we wish to use the three stage estimation procedure.

From equation (2), the first stage of the procedure regresses $Y_{i t}$ on $f\left(X_{i t}, \beta\right)$ using ordinary least squares. Secondly, the $\log$ of the squared residuals, $\hat{u}_{i t}^{2}$ from the first stage are used to obtain the estimates of the marginal effects of explanatory variables on the variance of maize yield $(\alpha)$. The third and final stage uses the antilog of the predicted value of the residuals obtained from the second stage as weights to estimate $\beta$ in the first argument in equation (2) through weighted least squares estimation. According to Just and Pope (1978) the resulting estimator of $\beta$ in the final stage is consistent and asymptotically efficient under a broad range of conditions and the whole procedure corrects for the heteroscedastic disturbance term.

Since the explanatory variables vary across the regions and time, it is possible to have omitted variables which are region specific or time specific. These unobserved region specific or time specific variables may blur the true relationship between maize yield and the considered explanatory variables as they may affect changes in yield. Panel data can be estimated using either a fixed effects model, which controls for omitted variables that differ between regions but are constant over time, or a random effects model, which considers that some omitted variables may be constant over time but vary across regions. We estimate the production function using the CobbDouglas functional form and assume fixed effect.

The presence of unit root is tested using the unit root test proposed by Levin- Lin-Chu (LLC) (2002). The test was chosen because it is well suited to datasets with relatively few panels and a larger number of time periods (i.e. it requires that the ratio of panels to time periods tends to zero). The test is a pooled Augmented Dickey-Fuller (ADF) test with differing lag lengths across the units of the panel. The null hypothesis is that the series contains a unit root and the alternative is that the series is stationary. 


\section{RESULTS AND DISCUSSION}

LLC panel unit root test was conducted to examine the time series properties of the variables of study. The null hypothesis of a unit root is rejected for the climatic variables in Table 1 and the first-differenced agronomic variables (maize yield and crop area) in Table 2. The detailed results of the unit root tests for the agronomic variables and climatic variables are displayed in Table 1 and Table 2 respectively.

Table 1 - LLC panel unit root test for agronomic variables

\begin{tabular}{|c|c|c|c|c|}
\hline- & \multicolumn{2}{|c|}{ Level } & \multicolumn{1}{c|}{ First difference } \\
\hline Ydjusted & $\begin{array}{l}\text { Adjuld } \\
\text { t statistic }\end{array}$ & P-value & $\begin{array}{l}\text { Adjusted } \\
\text { t statistic }\end{array}$ & P-value \\
\hdashline 1.220 & 0.888 & -2.833 & $0.002 *$ \\
\hline Crop area & -0.377 & 0.353 & -3.994 & $0.000^{*}$ \\
\hline
\end{tabular}

* indicates that the test statistics are significant at $5 \%$ level

Table 2 - LLC panel unit root test for climatic variables

\begin{tabular}{|c|c|c|}
\hline \multirow{2}{*}{-} & \multicolumn{2}{|c|}{ Level } \\
\cline { 2 - 3 } & Adjusted t statistic & P-value \\
\hline Rainfall & -3.723 & $0.000^{*}$ \\
\hline Temperature & -2.446 & $0.005^{*}$ \\
\hline
\end{tabular}

* indicates that the test statistics are significant at $5 \%$ level

Table 3 displays the regression coefficients for mean maize yield from stage three of the Just and Pope stochastic production function estimation procedure. The $\mathrm{R}^{2}$ value is 0.70 and the test result of F-statistic shows the function to be wellbehaved. The results show that a $1 \%$ increase in crop area will significantly increase mean maize yield by $0.92 \%$. Rainfall and temperature has a negative effect on mean maize yield though insignificant.

Table 3 - Mean yield results

\begin{tabular}{|c|c|c|}
\hline Response variable: Log (Yield) & - & - \\
\hline Variable & Coefficient & P-value \\
\hline Intercept & $2.089(1.073)$ & 0.055 \\
\hline Log (crop area) & $0.920(0.068)$ & $0.000 *$ \\
\hline Log (Temperature) & $-0.612(0.321)$ & 0.060 \\
\hline Log (Rainfall) & $-0.016(0.032)$ & 0.619 \\
\hline $\mathrm{R}^{2}$ & 0.70 & - \\
\hline F statistic & 65.42 & $0.000 *$ \\
\hline
\end{tabular}

Notes: standard errors in parentheses; * denotes significance at $5 \%$ level. Number of observation: 90 .
The elasticity for rainfall is computed as 0.016 and thus a $1 \%$ increase in rainfall will decrease mean maize yield by $0.02 \%$. Also, a $1 \%$ increase in temperature will likewise decrease mean maize yield by $0.6 \%$. These results are similar to the findings of Boubacar (2010). The author found his degree-days and precipitation intensity variables to be negatively related to mean maize yield. However, mean maize yield had a positive relationship with cultivated area.

Table 4 display the regression coefficients for yield variance from stage two of the Just and Pope stochastic production function estimation procedure. The $\mathrm{R}^{2}$ value is 0.08 and the test result of F-statistic shows the function to be wellbehaved. The results show that both crop area and temperature enlarge the yield variability. A $1 \%$ increase in crop area will increase yield variability by $1.6 \%$ while a $1 \%$ increase in temperature will cause maize yield variability to increase by $0.01 \%$. Rainfall will significantly reduce maize yield variability by $0.0001 \%$ with a $1 \%$ increase. These results corroborate the findings by Chen et al. (2004). The authors found that higher temperatures increase corn yield variability while increasing rainfall decreases the variance of corn yield.

Table 4 - Yield variance results

\begin{tabular}{|c|c|c|}
\hline $\begin{array}{l}\text { Response variable: } \\
\text { Log (Yield Variance) }\end{array}$ & - & - \\
\hline Variable & Coefficient & P-value \\
\hline Intercept & $-10.254(6.171)$ & 0.100 \\
\hline Log (crop area) & $1.627(2.292)$ & 0.480 \\
\hline Log (Temperature) & $0.008(0.009)$ & 0.356 \\
\hline Log (Rainfall) & $-0.0001(0.00004)$ & $0.008 *$ \\
\hline $\mathrm{R}^{2}$ & 0.08 & \\
\hline F statistic & 2.97 & $0.0365^{*}$ \\
\hline
\end{tabular}

The relationship between climatic variables and crop area on the mean and variance of maize yield is not well understood within the Ghanaian context. This paper therefore examined the effects of climatic variables and crop area on the mean and variance of maize yield in Ghana. The Just and Pope stochastic production function using the Cobb-Douglas functional form was employed. The results show that average maize yield is positively related to crop area and negatively related to rainfall and temperature. Furthermore, increase in crop area and temperature will enlarge maize yield variability while rainfall increase will decrease the variability in maize yield. Further investigations are needed to examine the effects of climatic variables and crop area on the quantiles of maize yield and variability. 


\section{REFERENCES}

Abrol, Y. P., \& Ingram, K. T. (1996). Effects of higher day and night temperatures on growth and yields of some crop plants. In F. Bazzaz, \& W. Sombroek eds: Global climate change and agricultural production: Direct and indirect effects of changing hydrological, pedological and plant physiological processes. John Wiley \& Sons Ltd, West Sussex, England. 123-140.

Aggarwal, P. K. \& R. K. Mall (2002). Climate Change and rice Yields in Diverse AgroEnvironment of India: Effects of Uncertainties in Scenarios and Crop Models on Impact Assessment, Climatic Change 52: $331-43$.

Boubacar, Inoussa (2010). The Effects of Drought on Crop Yields and Yield Variability in Sahel. Selected Paper prepared for presentation at the Southern Agricultural Economics Association Annual Meeting, Orlando, FL, February 6-9, 2010.

Chen, C., B. A. McCarl, \& D. E. Schimmelpfennig (2004). Yield Variability as Influenced by Climate: A Statistical Investigation, Climatic Change 66: 239-61.

Isik, M., S. Devadoss (2006). An Analysis of the Impact of Climate Change on Crop Yields and Yield Variability. Applied Economics 38: 835-44.

Joshi, N.P., Maharjan, K.L. \& Piya, L. (2011). Effect of Climate Variables on Yield of Major Food-crops in Nepal. A Time-series Analysis. Journal of Contemporary India Studies: Space and Society, Hiroshima University. Vol.1: 19-26,2011.

Just, R.E \& R.D. Pope (1978). Stochastic Specification of Production Function and Economic Implications. Journal of Econometrics 7(1): 67-86.

Just, R.E \& R.D. Pope (1979). Production Function Estimation and Related Risk Consideration. American Journal of Agricultural Economics 61(2): 276-284.

Levin, A., C.F. Lin, \& C.S. J. Chu. 2002. Unit root tests in panel data: Asymptotic and finite-sample properties. Journal of Econometrics 108: 1-24.

Lobell, D. \& Field, C. (2007). Global Scale Climate-Crop Yield Relationships and the Impacts of Recent Warming. Environmental Research Letter 2.
Mearns, L.O., C. Rosenzweig., R. Goldberg (1997). Mean and Variance Change in Climate Scenarios: Methods, Agricultural Application, and Measures of Uncertainty. Climatic Change, 35, 367-96.

Rockström, J., Folke, C., Gordon, L., Hatibu, N., Jewitt, G., Penning de Vries, F., Rwehumbiza, F., Sally, H., Savenije, H. \& Schulze, R. (2004). A Watershed Approach to Upgrade Rainfed Agriculture in Water Scarce Regions through Water System Innovations: An Integrated Research Initiative on Water for Food and Rural Livelihoods in Balance with Ecosystem Functions. Physics and Chemistry of the Earth 29: 1109-1118.

Rosenzweig C, Iglesias A, Yang XB, Epstein PR, Chivian E (2001). Change and extreme weather events. Implications for food production, plant diseases, and pests. Global Change Human Health 2(1), 90-104.

Rosenzweig, C. and Parry, M. L. (1994). Potential Impacts of Climate Change on World Food Supply. Nature 367: 133-138.

Saha A, Havenner A, Talpaz H (1997). Stochastic production function estimation: small sample properties of ML versus FGLS. Applied Economics 29: 459-469

SRID/MOFA, (2011). Agriculture Statistics 2010, Statistical Research and Information Directorate, Ministry of Food and Agriculture, Ghana.

You, L., Rosegrant, M. W., Wood, S. \& Sun, D. (2009). Impact of Growing Season Temperature on Wheat Productivity in China. Agricultural and Forest Meteorology 149: 1009-1014. 